DOI: https://doi.org/10.24867/15BE32Mirilovic

\title{
SISTEM ZA SKUPLJANJE I POSTAVLJANJE PRSTENJA SA MAŠINSKIM PREPOZNAVANJEM
}

\author{
RING PICK-AND-PLACE WITH MACHINE VISION
}

\author{
Stefan Mirilović, Milan Vidaković, Fakultet tehničkih nauka, Novi Sad
}

\section{Oblast - RAČUNARSTVO I AUTOMATIKA}

Kratak sadržaj - Zadatak rada predstavlja sistem za skupljanje $i$ postavljanje (Pick-and-Place) prstenja sa mašinskim prepoznavanjem. Softverski deo predstavljaju jedna WPF aplikacija, Halcon i Codesys. Hardverski deo predstavlja Fanuc robot CRX-10iA/L sa specijalno napravljenom hvataljkom $i$ kamerom. WPF aplikacija omogućava korisniku da pušta, pauzira i stopira robota, među ostalim funkcijama.

Ključne reči: WPF, C\#, Codesys, Fanuc Robot, Halcon, Mašinsko prepoznavanje

\begin{abstract}
This paper deals with a system for pick-andplacing rings using machine vision. Software portion of the system is a WPF application, Halcon and Codesys. Hardware portion is a Fanuc robot CRX-10iA/L with a custom-built gripper and a camera. WPF application allows the user to start, pause and stop the robot, among other functions.
\end{abstract}

Keywords: WPF, C\#, Codesys, Fanuc Robot, Halcon, Machine vision

\section{UVOD}

Zadatak rada predstavlja razvoj sistema za pick-and-place [1] prstenja koji koristi mašinsko prepoznavanje (eng. Machine vision) [2]. Ovakvi slični sistemi koriste se $\mathrm{u}$ raznim industrijama, od keksova do nakita, da zamene ljudsku radnu snagu i time, dugoročno gledano, smanjuju troškove i čine proizvodnju mnogo produktivnijom.

Za razvoj sistema se morala koristiti kombinacija raznih tehnologija i značajan deo rada je na njihovoj međusobnoj komunikaciji.

\section{OPIS HARDVERSKIH TEHNOLOGIJA}

Hardverski deo čine robot korporacije FANUC [3], model CRX-10iA/L, kamera Basler acA1920-25gc i specijalno napravljena hvataljka sa LED osvetljenjem.

\subsection{FANUC Robot CRX-10iA/L}

FANUC je japanska korporacija koja nudi proizvode i servise u polju automatizacije i najveći je proizvođač industrijskih robota na svetu.

\section{NAPOMENA:}

Ovaj rad proistekao je iz master rada čiji mentor je bio dr Milan Vidaković, red. prof.
Model CRX-10iA/L je jedan od tzv. kolaborativnih robota (eng. Collaborative robot ili Cobot) [4]. Kolaborativni roboti su predviđeni za bliski rad sa ljudima i zbog toga su u odnosu na uobičajene industrijske robote napravljeni od lakših materijala, imaju glađe ivice, dodatne bezbednosne funkcije, i ograničenja na brzini i sili da bi osigurali bezbednost $u$ radu.

Robot ima širok izbor različitih tipova ulaza i izlaza, od kojih su za ovaj rad najznačajniji digitalni ulazi i izlazi. Robot takođe podržava Ethernet/IP [5] konekcije, što će biti ključno za komunikaciju sa softverom.

\subsection{Basler acA1920-25gc kamera}

Kamera koja se koristi za mašinsko prepoznavanje je Basler acA1920-25gc, rezolucije 1920px x 1080px, 2MP, i može da snima 25 fps (frejmova u sekondi).

Kamera koristi GigE Vision [6] interfejs, što je standard uveden 2006. godine za industrijske kamere visokih performansi. On nudi okvir za prenos video zapisa velike brzine preko Ethernet mreže.

\subsection{Hvataljka}

$\mathrm{Na}$ robotu je nameštena specijalno napravljena hvataljka za prstenje. Hvataljka je povezana za dva ventila, ventili za regulator pritiska, a regulator za kompresor za vazduh.

Regulator ograničava maksimalni vezdušni pritisak na zadatu vrednost, koja je nameštena na $0.1 \mathrm{MPa}$ ili 1 bar. Dva ventila kontrolišu otvaranje i zatvaranje hvataljke, zaviseći od toga koji je od njih otvoren.

\subsection{Podloga}

Za najbolje rezultate mašinskog prepoznavanja mora se odabrati pogodna podloga za objekat koji se prepoznaje. Za prstenje je iznenađujuće najbolji izbor najobičniji blok papir za crtanje. Blok papir pati od bljeska i ne daje homogenu podlogu na slici, ali veliki kontrast bele pozadine i tamnih prstenja je prevladao i davao ubedljivo najbolje rezultate.

\section{OPIS SOFTVERSKIH TEHNOLOGIJA}

Za softverski deo rada su korišćeni CodeSys [7] i WPF (Windows Presentation Foundation) [8] aplikacija. Za mašinsko prepoznavanje je korišćen Halcon [9].

Za komunikaciju sa robotom je korišćen Ethernet/IP protokol. 


\subsection{Robotski softver}

Robot ima dva suštinski različita koordinatna sistema po kojim može da se pomera.

Jedan koordinatni sistem je Kartezijev (Dekartov) koordinatni sistem od šest osa:

- $\mathrm{x}$ - dužina,

- $\quad \mathrm{y}$ - širina,

- $\mathrm{z}$ - visina,

- $w$ - ugao rotacije oko $\mathrm{x}$-ose,

- $p$ - ugao rotacije oko y-ose $\mathrm{i}$

- $r$ - ugao rotacije oko z-ose.

Slikovno objašnjenje kartezijevog koordinatnog sistema na robotu može se videti na Slici 1.

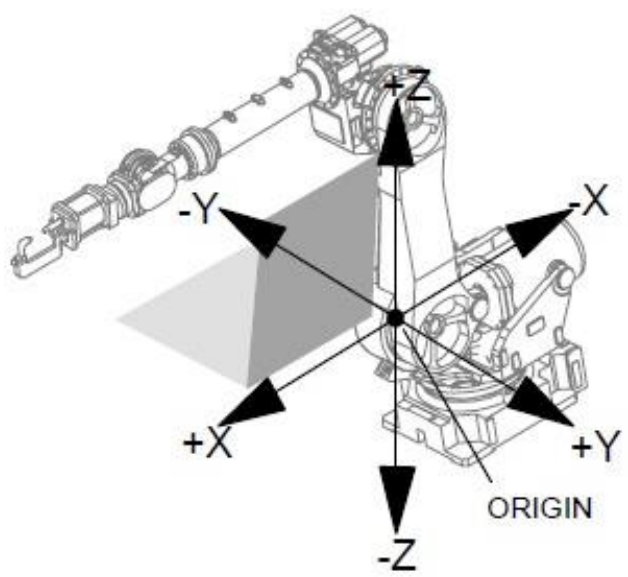

Slika 1. Kartezijev koordinatni sistem

Drugi koordinatni sistem se zove zglobni (eng. Joint). Kao što naziv sugeriše, ose ovog koordinatnog sistema su zglobovi robota i pošto model CRX-10iA/L ima šest zglobova, tako i zglobni koordinatni sistem ima šest osa: J1, J2, J3, J4, J5 i J6. Slikovno objašnjenje može se videti na Slici 2.

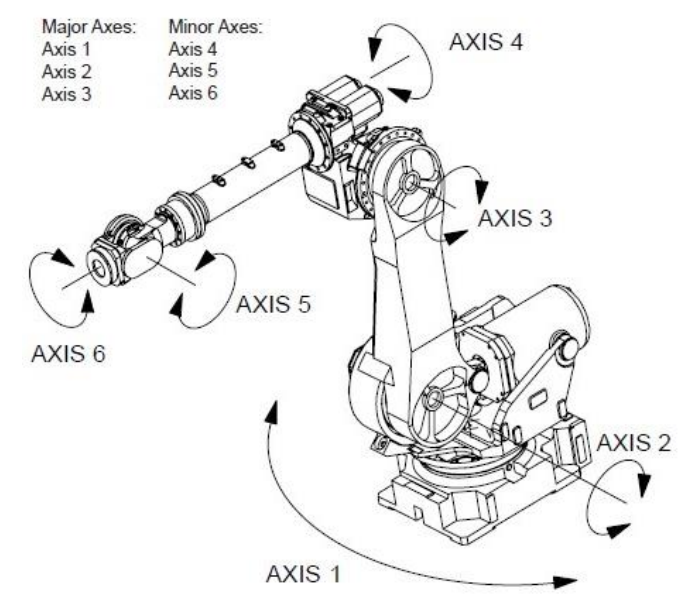

Slika 2. Zglobni koordinatni sistem

\subsection{Codesys}

Codesys je razvojno okruženje za programiranje kontrolerskih aplikacija po međunarodnom industrijskom standardu IEC 61131-3 [10]. Ove aplikacije rade na tzv. PLC-ovima (eng. Programmable logic controller) [11].
PLC je industrijski kompjuter koji je robustan i prilagođen za kontrolu proizvodnih procesa, kao što su montažne trake, mašine i roboti.

Codesys ima mogućnost da pretvori redovan računar $\mathrm{u}$ PLC sa njegovim Codesys Control Win V3. Ovaj alat je takođe Codesys-ov sistem izvršavanja ili rantajm sistem (eng. Runtime system) [12]. Rantajm sistem je neophodan za pokretanje koda napisanog u Codesys-u, jer Codesys ne generiše izvršne programe, kao što je .exe fajl, već zavisi od rantajm sistema da pokrene rantajm okruženje (eng. Runtime environment) u kojem se onda izvršava kod.

Po IEC 61131-3 standardu, Codesys nudi pet programskih jezika u svom razvojnom okruženju:

- IL (eng. instruction list) je programski jezik sličan asemblerskom, zastareo,

- $\quad$ ST (eng. structured text) je slično programiranju u $C$-u ili Pascal-u,

- LD (eng. ladder diagram) je dijagram koji omogućava programeru da virtualno spoji relejne kontakte i zavojnice,

- $\quad$ FBD (eng. function block diagram) je dijagram koji omogućava korisniku da brzinski programira boolean i analogne izraze i

- $\quad$ SFC (eng. sequential function chart) je dijagram pogodan za programiranje sekvencijalnih procesa i tokova.

\subsection{Windows Presentation Foundation}

Windows Presentation Foundation (WPF) je besplatan i open-source grafički podsistem za pravljenje desktop aplikacija na Windows-u. U WPF-u se koristi Extensible Application Markup Language (XAML) za definisanje korisničkog interfejsa (frontend), i C\# za programiranje funkcionalnosti (backend).

\subsection{Halcon}

MVTec Halcon je obiman softver za mašinsko prepoznavanje sa integrisanim razvojnim okruženjem (HDevelop). U smislu funkcionalnosti se može porediti sa OpenCV [13] bibliotekom. Verovatno najveća razlika između njih je to što je OpenCV besplatan za korišćenje i open-source, dok Halcon nije ni jedno ni drugo.

Halcon može da se koristi iz njegovog razvojnog okruženja HDevelop, ali može da se poziva njegov API iz C-a, C++-a, Visual Basic-a i C\#-a.

\section{OPIS IMPLEMENTACIJE}

Sistem čine WPF aplikacija i Codesys kontrolerska aplikacija, koji međusobno komuniciraju preko deljene memorije.

\subsection{Komunikacija sa Codesys-om}

Za komunikaciju sa Codesys-om, WPF aplikacija ima dve promenljive: inputVariables i outputVariables. InputVariables je struktura koja sadrži sve ulazne 
parametre, tj. parametre koje idu iz pravca Codesys u WPF. OutputVaribles je struktura koja sadrži sve izlazne parametre, iz pravca WPF u Codesys.

Komunikacija između WPF aplikacije i Codesys-a je uspostavljena preko deljene memorije, koja se kontinualno čita i piše u beskonačnoj petlji, koja se poziva preko BackgroundWorker klase. BackgroundWorker klasa izvršava operacije na zasebnoj niti, što dozvoljava spomenutoj petlji da se vrti kontinualno i asinhrono bez ometanja glavne niti.

Radi komunikacije se prave dva Memory-mapped fajla. Oni su neperzistentni fajlovi koji nisu povezani sa datotekom na disku.

Kada poslednji proces završi rad sa datotekom, podaci se gube. Ovaj vid komunikacije je odabran zbog njegove odlične brzine.

\subsection{Prepoznavanje prstenja}

Kao što je već rečeno, za prepoznavanje se koristi Halcon-ov API. Sa operacijom Decompose3 trokanalna (RGB, eng. Red, Green, Blue) slika koju kamera uslika se pretvori u tri jednokanalne slike, gde svaka odgovara jednoj boji od tri koje zajedno čine RGB. Originalna slika i jedna generisana se vide na Slikama 3. i 4.

Najveći kontrast između pozadine i prstenja davala je slika koja odgovara plavoj boji, pa se ona koristila dalje u programu.

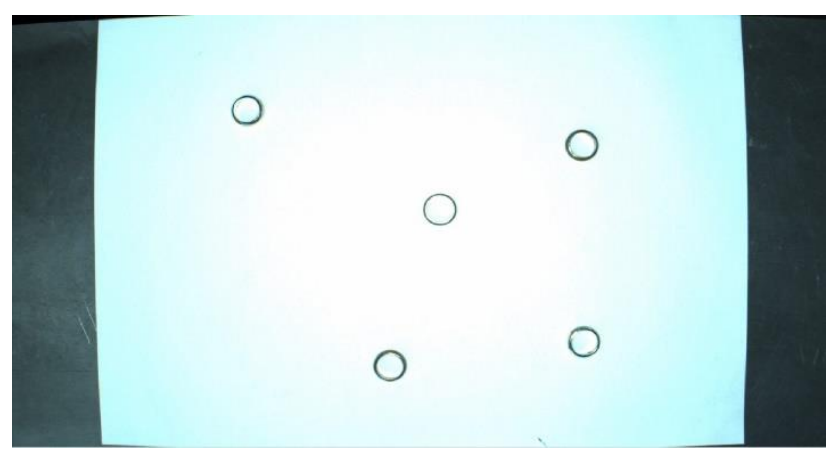

Slika 3. Originalna slika

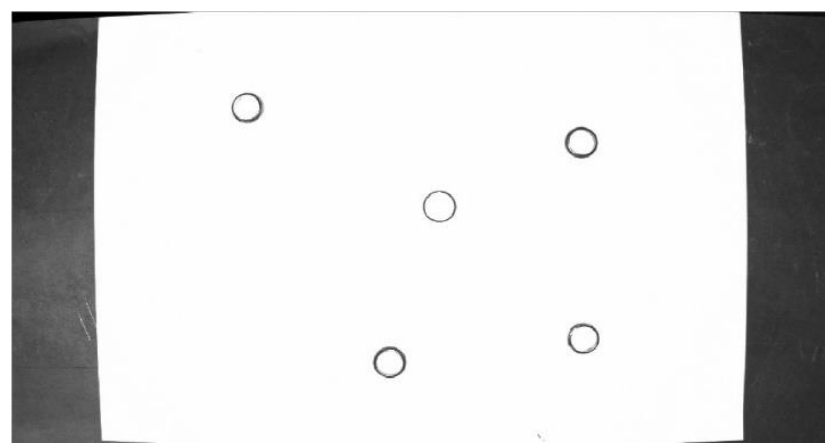

Slika 4. Izdvojena plava boja iz slike

Sledeća operacija je Threshold. Njen zadatak je izdvojiti sve piksele čija je vrednost sive boje između 0 i 150 (0 je crna boja, a 255 bela).

Praktično, ovaj korak je uklonio belu podlogu, a ostatak označio, kao što se vidi na Slici 5. Programski, sve boje slike su se pretvorile u nule $\mathrm{i}$ jedinice, gde su nule predstavljene crnom, a jedinice crvenom na Slici 5.

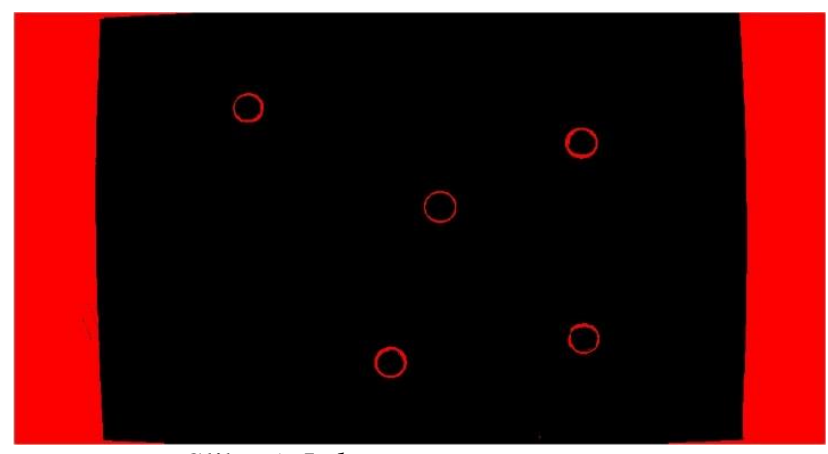

Slika 5. Izdvojene tamne površine

Sledeća operacija Connection čini da svaki region koji nije spojen sa drugim bude odvojena komponenta.

Ovo će kasnije omogućiti brojanje komponenti, tj. prstenja. Sledeća operacija FillUp popuni sve komponente koji su šuplje. Time se dobije Slika 6.

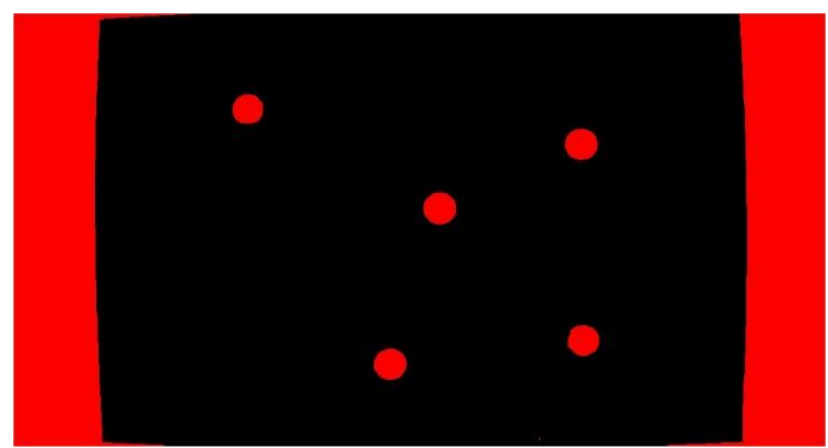

Slika 6. Popunjene šupljine

Sledeća operacija SelectShape čini više stvari; za svaku komponentu izračuna dve vrednosti:

- $\quad$ circularity - procenat koji predstavlja koliko se površina komponente poklapa sa krugom i

- $\quad$ area - vrednost površine komponente.

Kad ima ove dve vrednosti za sve komponente, izdvoji sve komponente koji zadovoljavaju sledeće uslove:

- $\quad 0.85<$ circularity $<1 \mathrm{i}$

- $400<$ area $<9999$.

Rezultat ove operacije vidi se na Slici 7.

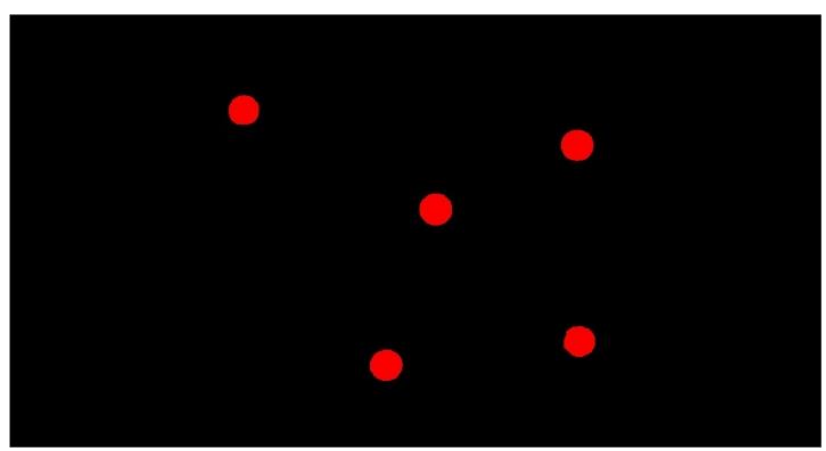

Slika 7. Rezultat SelectShape operacije

Potom iscrta na prozoru dobijeni rezultat sa Slike 7, što onda izgleda kao na Slici 8. 


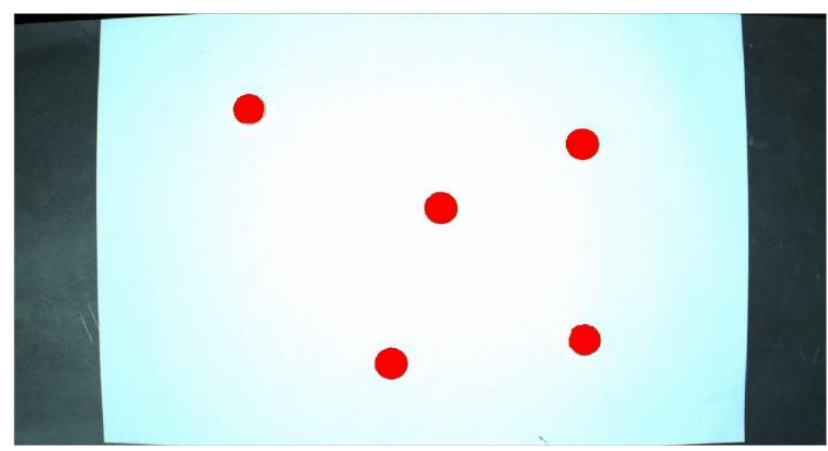

Slika 8. Konačni rezultat

Ovim je trebalo biti prepoznato svo prstenje, gde svaki prsten odgovara jednoj komponenti. Sledeći korak je onda prebrojati komponente sa funkcijom CountObj. Potom se traži row i column svake komponente, što predstavlja njegovu poziciju na slici. U gornjem levom uglu slike je row 0 i column 0 , a u donjem desnom je row 1080, a column 1920, što odgovara rezoluciji kamere (1920x1080 piksela). U ovakvom formatu, row i column su robotu neupotrebljivi, zato ih treba pretvoriti u x i y koordinate po robotskom koordinatnom sistemu.

Nad svim koordinatama se onda vrši operacija ImagePointsToWorldPlane koja vrši potrebnu konverziju i daje x i y koordinate u milimetrima. Od ovih koordinata se napravi pozicija koja se onda dodaje na listu pozicija koja se šalje Codesys-u.

\subsection{Korisnički interfejs}

Korisnički interfejs se sastoji od samo jednog prozora u dva režima. Režim menja mnogo elemenata interfejsa, automatski režim može se videti na Slici 9, a ručni na Slici 10.
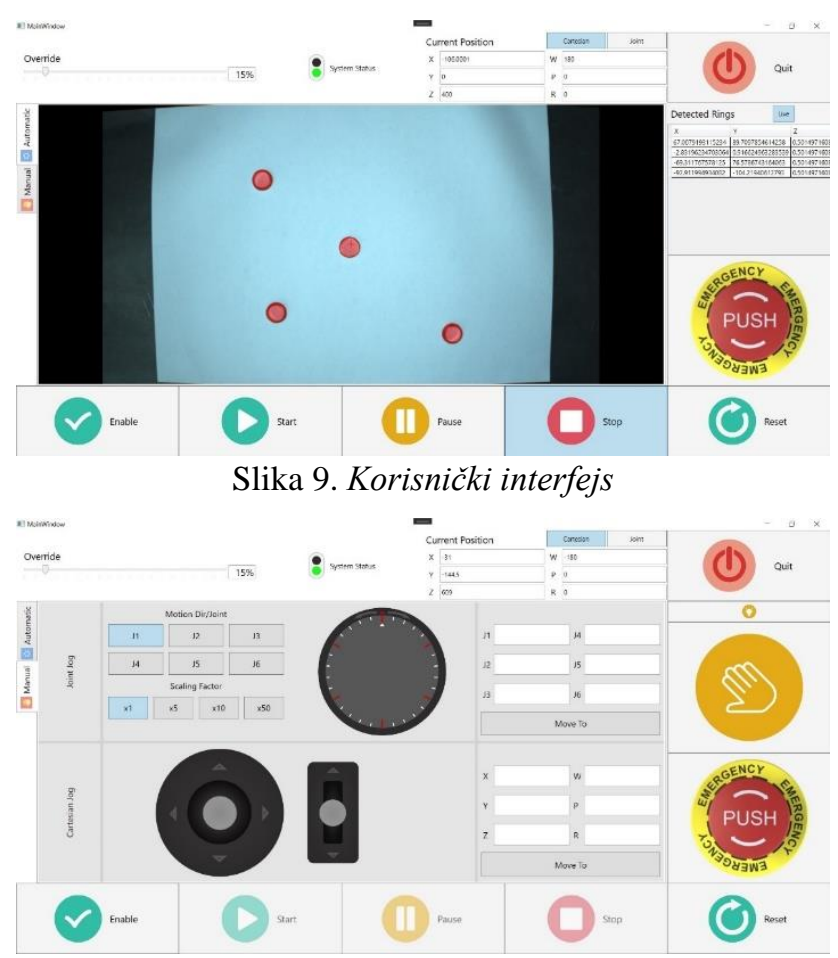

Slika 10. Korisnički interfejs u ručnom režimu

\section{ZAKLJUČAK}

Sistem je razvijen $u$ aktuelnim tehnologijama i sa modelom robota iz najnovije generacije kolaborativnih robota, koji su tek ušli u proizvodnju. Sistem u trenutnom stanju nema neku veliku praktičnu korist, ali daljim razvojem bi se to moglo lako promeniti. Jedan vid daljeg razvoja bi bila zamena statične podloge sa pokretnom trakom. Još jedna ideja za dalji razvoj bi bilo uključivanje i nekakve obrade prstenja nakon skupljanja, poput poliranja.

\section{LITERATURA}

[1] Pick-and-place

https://en.wikipedia.org/wiki/Pick-and-place machine

[2] Machine vision

https://en.wikipedia.org/wiki/Machine_vision

[3] FANUC

https://en.wikipedia.org/wiki/FANUC

[4] Collaborative robot

https://en.wikipedia.org/wiki/Cobot

[5] Ethernet/IP

https://en.wikipedia.org/wiki/EtherNet/IP

[6] GigE Vision

https://en.wikipedia.org/wiki/GigE_Vision

[7] Codesys

https://en.wikipedia.org/wiki/CODESYS

[8] Windows Presentation Foundation

https://en.wikipedia.org/wiki/Windows_Presentation_Foundatio

$$
\underline{\mathrm{n}}
$$

[9] Halcon https://www.mvtec.com/products/halcon

[10] IEC 61131-3

https://en.wikipedia.org/wiki/IEC_61131-3

[11] Programmable logic controller

https://en.wikipedia.org/wiki/Programmable_logic_controller

[12] Runtime system

https://en.wikipedia.org/wiki/Runtime_system

[13] OpenCV

https://en.wikipedia.org/wiki/OpenCV

\section{Kratka biografija:}

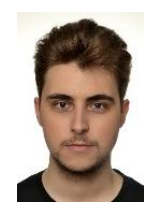

Stefan Mirilović rođen je 04.05.1997. u Bečeju. Završio osnovnu školu ,Zdravko Gložanski“ u Bečeju 2012. godine i Gimnaziju Bečej 2016. godine. godine. Završio osnovne akademske studije na Fakultetu tehničkih nauka u Novom Sadu, smer Računarstvo i automatika 2020. godine. Nakon završenih osnovnih studija upisao je master akademske studije na istom fakultetu, smer Računarstvo i automatika, modul Elektronsko poslovanje. kontakt: stefan.mirilovic@gmail.com

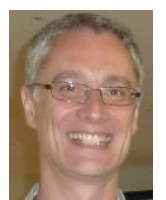

Milan Vidaković završio je doktorske studije 2003. godine na Fakultetu tehničkih nauka $u$ Novom Sadu. Na istom fakultetu je 2014. godine izabran za redovnog profesora iz oblasti Primenjene računarske nauke i informatika. 